\title{
Study results of the on-board weight control system as exemplified by feed mixture preparation using a trailed feed mixer-and- distributor
}

\author{
Vladimir Sirovatka ${ }^{1}$, Alexey Dorokhov ${ }^{2}$, Vladimir Kirsanov ${ }^{2}$, Dmitriy Pavkin $^{2}$ and Evgeniy \\ Nikitin,"* \\ ${ }^{1}$ All-Russian Research Institute of Livestock Farming Mechanization, 31, Znamya Oktyabrya, Russia \\ ${ }^{2}$ Federal Scientific Agroengineering Center VIM, 5, $1{ }^{\text {st }}$ Institutskaya Str., 109428, Moscow, Russia
}

\begin{abstract}
The study purpose is to determine the operational efficiency of the on-board weight control system using the technological process of preparing the feed mixture as an example. The Daily TMR Manager, an on-board weight control system, consisting of communication components, digital indicators with information on the display installed in the operator's cab (of the mixer-and-distributor) and loader operator, and the "Feeding Management" software package were used as a means of controlling the technological process of preparing the feed mixture. The recorded data were transmitted via Internet resources to a cloud storage that provides round-the-clock access to information. The process of evaluating the performance of the weighing system involved loading stalky bulk and loose concentrated components of the feed mixture. Analyzing the evaluation results of the weight control protocols with the recorded data, the authors have determined the influence of human-machine interaction on accuracy, and revealed that the material dosing error increases inversely with the dosed material mass. To improve the operational characteristics of on-board weight control systems it is recommended to install weight sensors on the loader boom to reduce the error when dispensing materials and increase the operator's response speed.
\end{abstract}

\section{Introduction}

As the demand analysis for services in the global economy shows, logistics has been one of the most stably growing economic areas since 2008, increasing by an average of 1.1$3.7 \%$ per year. This is true for the rate of development of international and regional logistics: especially high dynamics is observed in the areas connecting the central regions of Russia, as well as in the areas connecting the regional centers of Russia with the logistics centers of China and European countries. The development of logistics is facilitated not only by Russia's accession to the WTO, but also by an increase in the international trade of consumer goods as a whole [1].

*Corresponding author: Evgeniy.nicks@yandex.ru 
Taking into account the above trends, the requirements for cargo transportation are being tightened, especially in recent years. This has affected the transportation of goods along federal roads by truck-type vehicles. The main criterion that tightens the transportation requirements is the amount of cargo weight acting on the trailer chassis and weight distribution along each axis. The considered limitations have made a significant impact on the ways of organizing the transportation of farm produce while performing various technological operations (sowing grain and root crops, forage production, transporting the feed mixture to livestock facilities) [2.11]. As most of the transport logistics stations, including the agricultural ones, are not able to organize weight control points, there is a kind of disagreement between the controlling services and the organizers of transportation. Because of this, many developers offer various technical solutions implemented in the form of automatic on-board weight control systems containing straingauge elements fixed between the chassis and the frame of the trailer's filled tank [3].

As such technologies for cargo batching are being developed, the principle of weighing transported materials on board a vehicle has become widely used in the construction industry for making sand and gravel mixtures of exact proportions, sand and cement mixtures, etc. In their turn, farm enterprises apply this method for preparing total mixed rations (typically abbreviated as TMR) using a mixer dispenser [4], where it is necessary to observe a clear ratio of components, the number of which varies from 3 to 7 [5], followed by mixing and controlling the dynamics of the material discharge.

It is worth noting that the introduction of automatic systems operating in an autonomous mode, including on-board weight control systems, requires taking into account the technological features of loading materials [6]. These features largely determine the probability of error in their filling. That is why on-board weight control systems must be equipped with systems for analyzing foreign metal bodies found when harvesting and preparing the feed base [7].

In the course of research, the authors evaluated the effectiveness of the Daily TMR Manager automatic weight control system, taking into account the above factors. The analysis performed made it possible to automatically control the loading of the feed mixture components with a bucket loader, taking into account the requirements of specialists who approve the feeding standards [8]. The research process of the weighing system included sequential supply of materials with remote monitoring of strain-gauge elements using wireless communications and software with neural network algorithms of process monitoring $[9,10,12]$. To ensure a reliable evaluation, the metered materials were evaluated by groups of components (concentrated and bulk ones) [13]. Taking into account the fact that the use of robotic platforms for the feed mixture distribution is gaining popularity every year [14], the dynamic monitoring of feed mixture distribution also increases the relevance of studies of the effectiveness of weight control systems (metering) $[15,16]$.

\section{Purpose of the study}

The presented study aims at determining the efficiency of the on-board weight control system using an example of the technological process of preparing the feed mixture.

\section{Materials and Methods}

To evaluate the effectiveness of the on-board weight control system, the authors analyzed the process of preparing feed mixture (Fig. 1). The mixer dispenser was equipped with the Daily TMR Manager system, consisting of communication components, digital indicators 
with information displayed on the scoreboard installed in the tractor operator's cabin (the control point of the coupled mixer-and-distributor) and the loader operator, as well as the "feeding management" software, operating in accordance with the concept (Fig. 2).

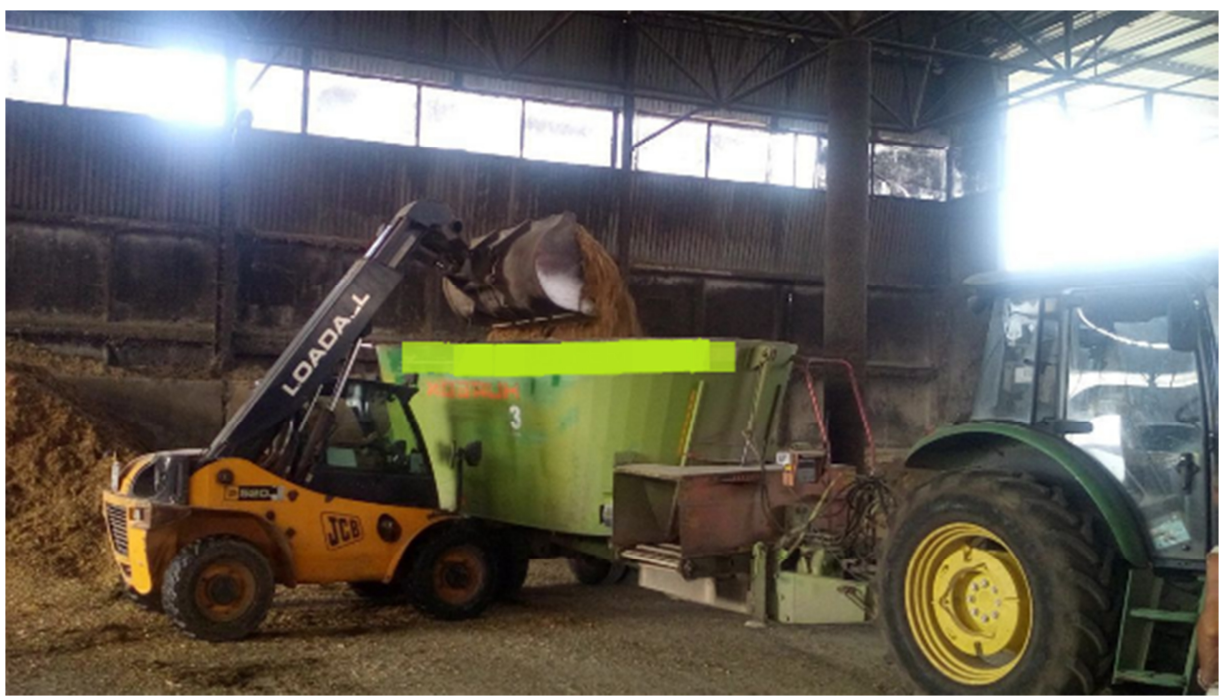

Fig. 1. Machines involved in the research process.

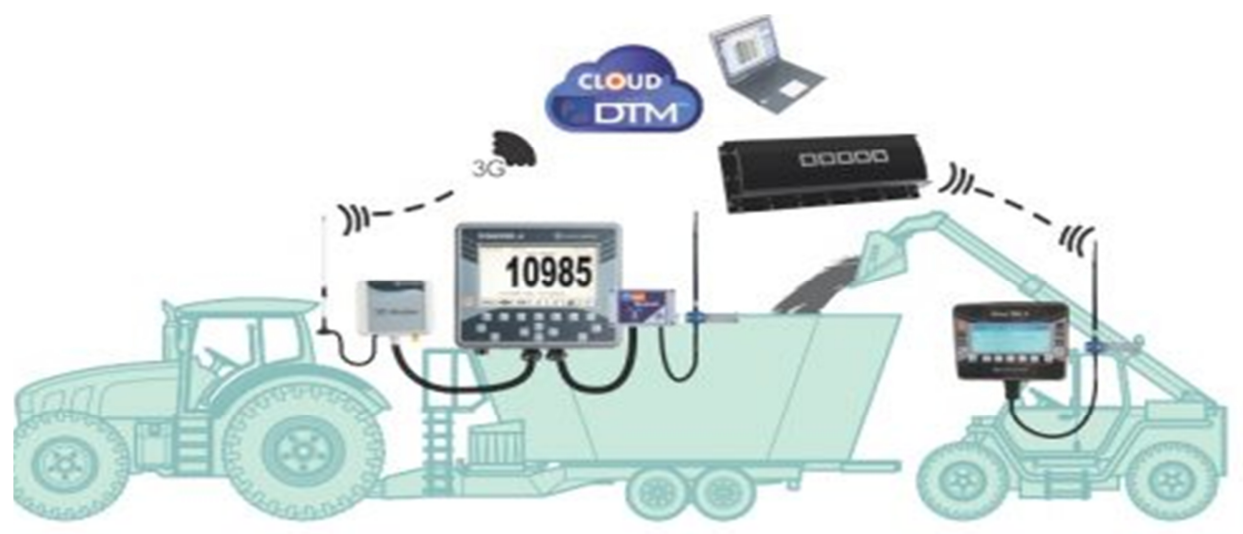

Fig. 2. Schematic diagram of the on-board weighing system operation.

The generated data control protocols based on the loading process results were processed using the MS Excel software package.

\section{Results}

The report on the results of loading the components into the mixer-dispenser is presented in Fig. 4. It was prepared by monitoring the technological process of preparing the feed mixture using the Daily TMR Manager on-board weight control system, which consists of communication components, digital indicators with information displayed on the board installed in the tractor cab (coupled with the mixer-distributor) and a loader operator. 


\begin{tabular}{|l|l|l|l|l|l|l|l|l|}
\hline $\begin{array}{l}\text { Inv. } \\
\text { number of } \\
\text { the } \\
\text { component }\end{array}$ & Components & $\begin{array}{l}\text { Total target } \\
\text { weight }\end{array}$ & $\begin{array}{l}\text { Target wheight } \\
\text { shown in the } \\
\text { sensing } \\
\text { element }\end{array}$ & $\begin{array}{l}\text { \% of } \\
\text { correction }\end{array}$ & $\begin{array}{l}\text { Target } \\
\text { weight (in } \\
\text { light of } \\
\text { error) }\end{array}$ & Loaded & $\begin{array}{l}\text { Inaccuracy } \\
\text { (\%) }\end{array}$ & $\begin{array}{l}\text { Operator's } \\
\text { error in } \\
\text { weighing } \\
\text { (\%) }\end{array}$ \\
\hline 2 & Haylage & 44.220 .00 & 44.220 .00 & 0.00 & 44.220 .00 & 45.385 .00 & 2.63 & 2.66 \\
\hline 3 & Com silage & 14.580 .00 & 14.580 .00 & 0.00 & 14.580 .00 & 14.955 .00 & 2.57 & 2.57 \\
\hline 15 & Molasses & 5.025 .00 & 5.025 .00 & 0.00 & 5.025 .00 & 5.520 .00 & 9.85 & 9.85 \\
\hline 41 & Carrots & 4.785 .00 & 4.785 .00 & 0.00 & 4.785 .00 & 4.335 .00 & -9.40 & 58.10 \\
\hline 42 & Haylage No.10 & 18.600 .00 & 18.600 .00 & 0.00 & 18.600 .00 & 19.080 .00 & 2.58 & 2.63 \\
\hline 43 & $\begin{array}{l}\text { Com silage } \\
\text { No.5 }\end{array}$ & 39.380 .00 & 39.380 .00 & 0.00 & 39.380 .00 & 40.855 .00 & 3.75 & 5.09 \\
\hline 50 & Mixed fodder & 15.215 .00 & 15.215 .00 & 0.00 & 15.215 .00 & 17.880 .00 & 17.52 & 17.65 \\
\hline 51 & Camage & 7.500 .00 & 7.500 .00 & 0.00 & 7.500 .00 & 9.735 .00 & 29.80 & 34.47 \\
\hline \hline & & 149.305 .00 & 149.305 .00 & 0.00 & 149.305 .00 & 157.745 .00 & $\mathbf{5 . 6 5}$ & $\mathbf{8 . 4 3}$ \\
\hline
\end{tabular}

Fig. 3. Data Protocol Form of the weight control system.

The Protocol (Fig. 3) is not editable (Russian-speaking license) - for agricultural JSC "Zelenogradskoe", Moscow region, Pushkin district, village of Eldigvino

Name of lines: Inv. number of the component; Components; Total target weight; Target weight shown in the sensing element; \% of correction (based on analysis results); Loaded; Inaccuracy (\%); Operator's error in weighing (\%)

The name of the column: Haylage 4; Corn silage 9; Molasses; Carrots; Haylage No.104; Corn silage No.5; Mixed fodder

Using MS Excel software and a data analysis package, the authors have found that when loading concentrated components of a lower mass relative to the bulk ones, the probability of error between the required rate of the loaded material and the mass of incoming material tended to increase.

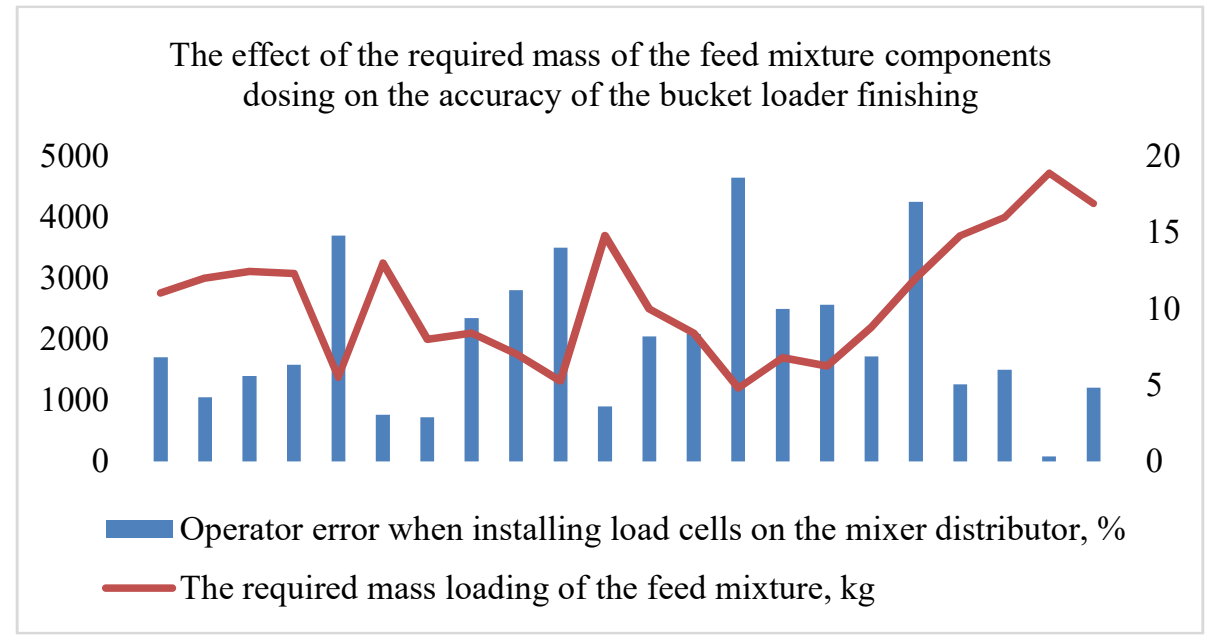

Fig. 4. Protocol evaluation results of component dosing errors with the Daily. TMR Manager weight control system. 
The analysis of the obtained relationship has shown that the wireless communication means transmitting data from the weight system of the mixer-distributor to the loader operator's scoreboard provide information with a delay, which slightly slows down the operator's response. Based on the results obtained, we decided to use the valves of the loader's hydraulic system with an analysis of the pressure exerted on the loader boom. The proposed concept was pre-modeled in the Matlab artificial environment with the Simulink visualization package using the Simscape Hydraulic libraries and the Sinks information processing components, Fig. 5.

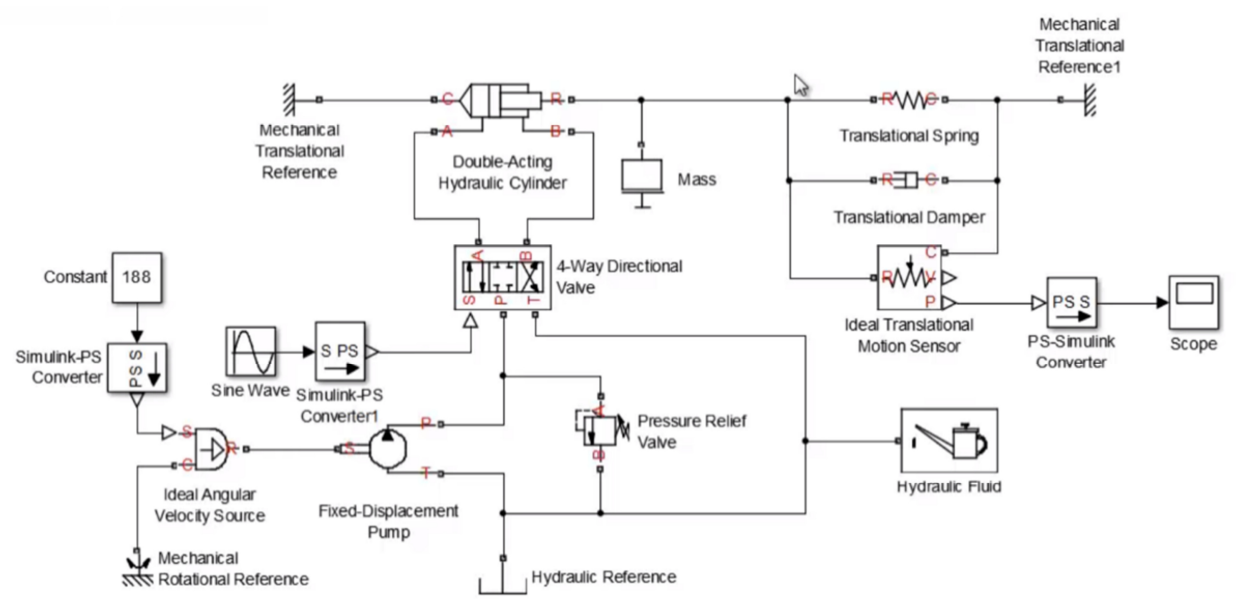

Fig. 5. Model of the hydraulic system for measuring the load on the loader boom in the Matlab Simulink environment.
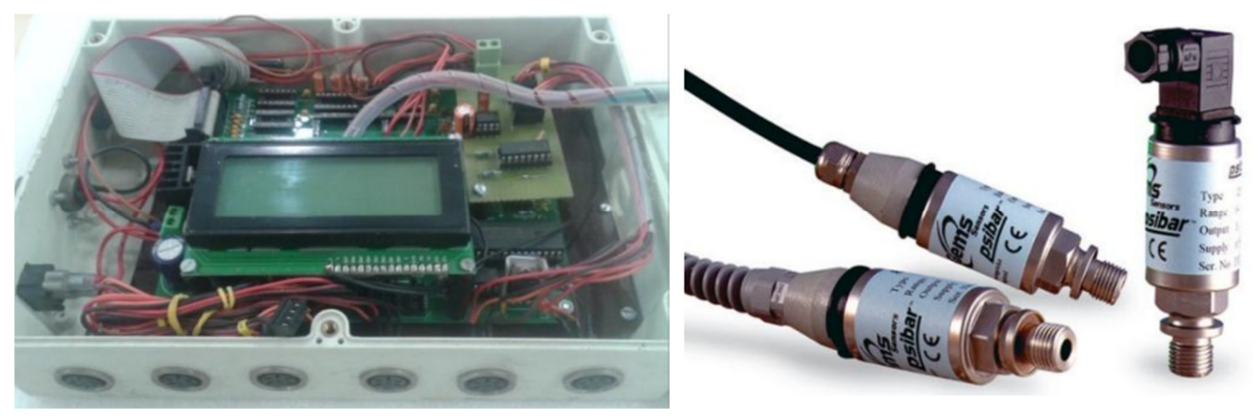

Fig. 6. Weight control components for bucket loaders.

The results assessing the error of filling the feed mixture components into the mixerdistributor are analytically processed and presented in Fig. 7. 
The effect of the required mass of the feed mixture component metering on the accuracy of the bucket loader finishing

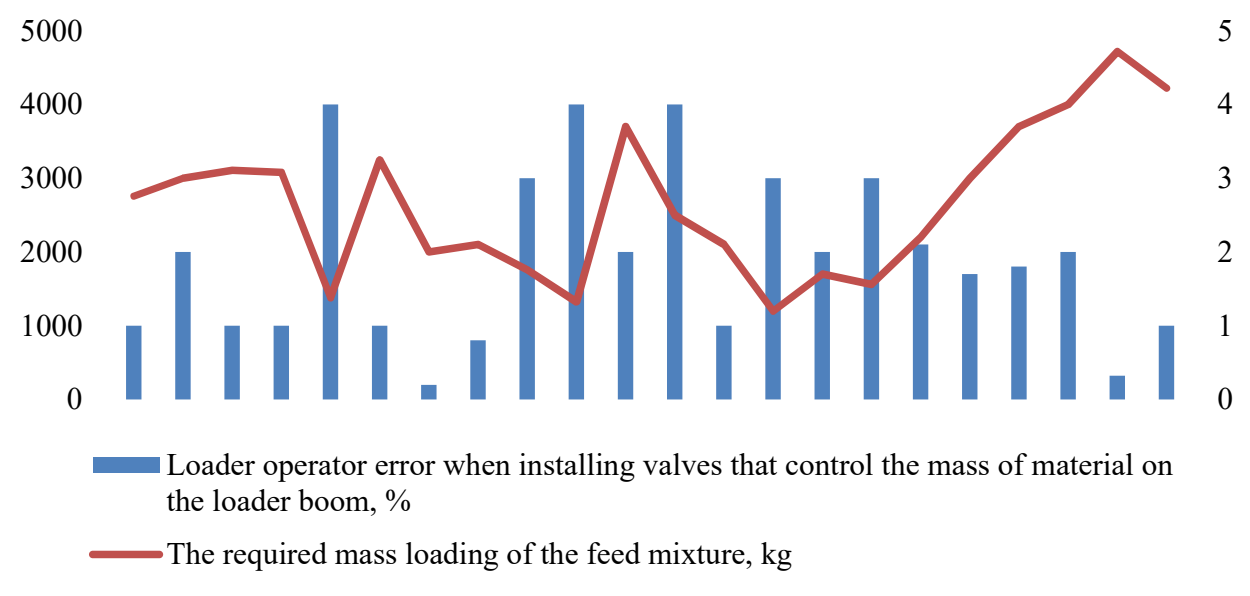

Fig. 7. Protocol evaluation results of component dosing errors with the proposed weight control system.

\section{Conclusions}

1. Based on the study results, it was found that the error in the operation of weight control systems increases inversely with the mass of material being loaded in the loader bucket.

2. Installing calibrated valves that fix the load on the loader boom, which was converted into the mass indicator of the dosed material by means of a programmable controller, allowed reducing the metering error rate.

\section{Acknowledgments}

The research was carried out within the framework of the State Program for agricultural development for 2013-2020 and the Decree of the Government of the Russian Federation No. 996 dated August 25, 2017 "On approval of the scientific and technical program for agricultural development for 2017-2020"

\section{References}

1. M.A. Semenov, O M Bolshunova, A. Korzhev, A. Kamyshyan, IOP Conference Series: Earth and Environmental Science 87 (2017) doi:10.1088/1755$1315 / 87 / 2 / 022017$

2. E.A. Nikitin, A.S. Dorokhov, D.Yu Pavkin, Tekhnika i oborudovaniye dlya sela 11, 32-34 (2019) doi: 10.33267/2072-9642-2019-11-32-34

3. N.R. Makange, R.P. Parmar, N. Sungwa, Advances in Life Sciences 5 (2016)

4. A. Haselmann, A. Zehetgruber, K. Fuerst-Waltl B. Zollitsch, W.K. Wilhelm, Journal of Dairy Science 11, 8839-8849 (2019) doi: 10.3168/jds.2018-16191

5. M.I. Chernovol, M.O. Sviren, R.V. Kisiliov, Agricultural Science and Practice 1, 17-22 (2018) doi: 10.15407/agrisp5.01.017 
6. I. Kovacev, Actual Tasks on Agricultural Engineering 45, 523-2 (2017)

7. C. Bisaglia, E. Romano, Applied Engineering in Agriculture 1, 55-61 (2017) doi: 10.13031/aea.11722

8. K.L. Samuelson, M.E. Hubbert, M.L. Galyean, C.A. Loest, Journal of Animal Science 6, 2648-2663 (2016) doi: 10.2527/jas.2016-0282

9. Z.K. Jin, Z.Y. Liang, P.F. Guo, M.W. Zheng, Asian Journal of Control 10 (2019) DOI: 10.1002/asjc. 2255

10. E. Leon, M. Mariano, Energy Conversion and Management 114, 89-99 (2016) 10.1016/j.enconman.2016.02.002

11. E. Charmley, T.L. Gowan, J.L. Duynisveld, Australian Journal of Experimental Agriculture 6, 831-835 (2006) doi: 10.1071/EA05314

12. Z. Zhang, H. Liang, IEEE Transactions on Fuzzy Systems 27, 1793-1806 (2016) doi: 10.1109/TFUZZ.2019.2891236

13. Z. Zhang, H. Liang, Canadian Journal of Animal Sciences 3, 281-290 (2016) doi: 10,4141 / A04-062

14. W.E. Dixon, D.M. Dawson, E. Zergeroglu, A. Behal, IEEE Transactions on Systems Man and Cybernetics Part B-Cybernetics 3, 341-352 (2015) doi: 10.1109/3477.931519

15. M. Sistkova, M. Psenka, V. Kaplan, J. Potesi, J. Cernin, Journal of Microbiology Biotechnology and Food Sciences 1, 60-63 (2015) doi: 10.15414/jmbfs.2015.5.1.60-63

16. C.E. Coppock, D.L. Bath, B. Harris, Journal Of Dairy Science 6, 1230-1249 (2015) doi: $10.3168 /$ jds.S0022-0302(81)82698-7 